\title{
Retorika Stand Up Comedy dan Public Speaking Komunitas Stand Up Indo Lampung
}

\author{
Ramadani Ilham ${ }^{1}$, Nuriyati Samatan ${ }^{2}$ \\ Fakultas Ilmu Komunikasi, Universitas Gunadarma \\ ramadani1st@gmail.com, nuriyatisamatan@gmail.com
}

\begin{abstract}
ABSTRAK
Stand up comedy dikenal sebagai seni pertunjukan komedi yang prakteknya dilakukan oleh satu orang bermonolog dan disaksikan oleh audiens ramai. Stand up comedy umumnya dilakukan secara live (langsung) dan merupakan one man show. Penelitian ini dilakukan dengan tujuan untuk memperluas wawasan retorika dalam praktiknya ke dalam seni stand up comedy. Penelitian ini dilakukan dengan menggunakan 2 teori yaitu Teori Retorika Aristoteles dan Teori Public Speaking Stephen E. Lucas, dan metode yang digunakan dalam penelitian ini adalah deskriptif kualitatif dengan teknik pengumpulan data yang digunakan yaitu observasi, wawancara, dan dokumentasi. Hasil penelitian ini menemukan bahwa terdapat keterkaitan antara karakteristik kegiatan stand up comedy dengan kegiatan retorika khususnya komunikasi publik. Kemudian hasil dari wawancara dengan komika komunitas Stand Up Indo Lampung, ketiga informan menyepakati bahwa pertunjukan stand up comedy dilakukan dengan menggunakan 5 kanon retorika Aristoteles yang di antaranya yaitu: penemuan, pengaturan, gaya, memori, dan penyampaian. Dari penelitian pada kemampuan public speaking ketiga informan diperoleh metode penyampaian pesan yang digunakan dalam kegiatan stand up comedy adalah speaking extemporaneously yang digabungkan dengan sedikit improvisasi dari berbicara spontan, dan komika melakukan pemanfaatan kepiawaian public speaking pada praktek stand up comedy dengan menampilkan manipulasi penggabungan aspek-aspek penting aset suara (the speakers voice), dan gerakan-gerakan tubuh (the speakers body).
\end{abstract}

Kata-kata Kunci: Retorika, Stand Up Comedy, Stand Up Indo

\section{Stand Up Comedy Rhetorics and Public Speaking Stand Up Indo Lampung Community}

\begin{abstract}
Stand up comedy known as a comedy show that practically performed by one man doing monologue, and witnessed by public audience. Usually the form of stand up comedy is a live show and categorized as one man show. This research aims to expanding rhetoric knowledge and it practice into the art of stand up comedy. This research uses the theory of Aristotelian rhetoric and Stephen E. Lucas public speaking theory. And this research uses qualitative descriptive method which the data collection techniques are observation, interviews, and documentation. The results of the research found out that there is a relation between the caractheristics of stand up comedy activites and rethorical activities particularly public communication. Then the results from the interview with the Stand Up Indo Lampung community comics, the three informant agreed that the stand up comedy show is performed by uses the 5 (five) Aristotelian rhetorical canon which is: discovery, arrangement, style, memory, and delivery. From research on the three informant public speaking skills, the mehod of delivery uses in stand up comedy activities is speaking extemporaneously combined with a few improvitation of spontaneous speech, and the comics uses the public speaking skills to show manipulation of the speakers voice and the speakers body.
\end{abstract}

Keywords: Rhetoric, Stand Up Comedy, Stand Up Indo

Published: September 2021

ISSN: 2622-5476 (cetak), ISSN: 2655-6405 (online) Website: https://jurnal.amikom.ac.id/index.php/pikma 
Jurnal PIKMA: Publikasi Media Dan Cinema, Volume 4, No. 1, September 2021, hlm 17-24

\section{PENDAHULUAN}

Seni retorika adalah menggunakan kemampuan berbicara untuk menyalurkan informasi kepada khalayak dengan efektif, diwaktu yang tepat, dan menjadikan bahasa sebagai alat baik secara lisan maupun dengan tulisan. (Mulyana, 2014) Komunikasi dalam fungsi sosial, yakni komunikasi mampu menghasilkan kesenangan ketika terjadi proses interaksi masyarakat. Komunikasi yang digunakan sebagai hiburan dapat berbentuk verbal maupun non verbal. Komunikasi berdasarkan bentuk verbal merupakan sarana utama untuk menyatakan pikiran, perasaan, dan maksud kita. Sementara, Komunikasi berdasarkan bentuk non verbal merupakan penggunaan isyarat yang bukan katakata untuk melengkapi makna-makna bahasa verbal.

Komunikasi yang dimaksud mampu menghasilkan kesenangan atau hiburan secara verbal ketika seseorang dengan sengaja menggunakan kepiawaian berbicaranya untuk merangkai hal-hal lucu menjadi pesan lelucon (humor) dengan tujuan memberikan perasaan terhibur kepada lawan bicaranya. Sementara komunikasi non-verbal sebagai fungsi hiburan atau kesenangan adalah pesan-pesan yang wujudnya bukan lisan (kata-kata) seperti mimik wajah, gesture, warna, jenis pakaian, riasan, atau atribut sebagai simbol-simbol yang memang digunakan untuk melengkapi komunikasi verbal dalam menghibur lawan bicara.

Komunikasi dalam fungsi hiburan sangat berkembang hingga muncul seni yang sedang menyebar luas dan diminati masyarakat Indonesia yaitu stand up comedy. Jika dilihat dari kegiatannya, peneliti yakin bahwa stand up comedy merupakan seni yang menggunakan retorika dan komunikasi sebagai fungsi hiburan.

Perkembangan stand up comedy di Indonesia belum terlalu lama, seni ini tergolong baru dan masih perlu banyak waktu untuk terus berkembang. Stand Up Comedy tercatat memiliki perkembangan yang lambat dibanding negara lain khususnya Amerika. Hal tersebut sangat lumrah dilihat dari perkembangan awalnya, Stand $U p$ Comedy berkembang lebih dulu di kawasan Eropa dan Amerika sejak abad ke-19 (Nugroho \& Ari, 2012).

Perlu diketahui bahwa ada hal unik ketika seorang Stand Up Comedian (komika dalam bahasa modern) menyampaikan materinya. Melihat dari prespektif komunikasi, gaya komika dalam berkomunikasi tidak hanya sekeder melemparkan lelucon seperti komedian lainnya, humor mereka merupakan pesan yang dikemas dalam bentuk sindirian atau kritikan yang dirangkai sedemikian rupa agar terdengar lucu ditelinga pendengarnya. Dengan gaya yang khas tersebut, walaupun merupakan bentuk dari satir tetapi pendengar tidak akan merasa tersinggung apalagi marah, stand up comedy adalah cara baru dalam menyalurkan aspirasi kepada masyarakat, tentu lebih disukai dan antusiasme masyarakat yang tinggi.

Berkaitan dengan perkembangan seni retorika dan praktek stand up comedy, regenerasi dan pembagian ilmu-ilmu stand up comedy dilakukan oleh komika dengan membentuk suatu 
Jurnal PIKMA: Publikasi Media Dan Cinema, Volume 4, No. 1, September 2021, hlm 17-24

wadah yang menjadi tempat sharing dan mengasah kemampuan berkomunikasi yaitu melalui wadah organisasi. Organisasi resmi dari stand up comedy di Indonesia adalah Stand Up Indo. Stand Up Indo telah menjadi pusat dari aktivitas resmi stand up comedy dan terus berkembang mewadahi para peminat stand up comedy dengan membentuk cabang diberbagai wilayah di Indonesia. Stand up comedy dan Stand Up Indo telah menyebar ke daerah-daerah di Indonesia seperti komunitas Stand Up Indo Jakpus, Stand Up Indo Depok, Stand Up Indo Yogyarakata, dan berbagai daerah lainnya. Kemudian komunitas yang menjadi pilihan peneliti dalam penelitian ini adalah komunitas Stand Up Indo Lampung.

Komunitas Stand Up Indo Lampung didirikan pada 1 Desember 2011 yang dibentuk oleh seorang komika bernama Adolf Hidayat atau lebih dikenal dengan Bung Dolop. Bung Dolop membentuk Stand Up Indo Lampung dengan melakukan open mic perdana di Rumah Putih Bandar Lampung. Semenjak didirikan hingga hari ini komunitas Stand Up Indo Lampung telah memiliki 20 orang anggota dengan 15 anggota diantaranya berstatus aktif organisasi. Saat ini, komunitas Stand Up Indo Lampung diketuai oleh komika yang bernama A. Nur Chammin Al Mufid atau yang lebih dikenal dengan nama panggungnya yaitu Mufid.

Tujuan dari didirikannya komunitas Stand Up Indo Lampung adalah agar para komika asal daerah Lampung memiliki wadah yang membuka jalan bagi peminat stand up comedy memiliki tempat untuk tampil dan menunjukan kemampuan mereka diberbagai tempat yang sudah disediakan oleh komunitas sehingga para komika tersebut memiliki kesemptan untuk berkarir sebagai pelaku stand up comedy yang memiliki pengalaman dan sudah punya jam terbang yang tinggi. Salah satu bukti kegiatan dari komunitas Stand Up Indo Lampung untuk para komika daerah Lampung adalah diadakannya open mic (combud) mingguan yang bertempat di warung nongkrong. Kemudian, contoh-contoh lomba dan acara yang telah diadakan oleh komunitas Stand Up Indo Lampung yaitu Stand Up Nite 1, Friday Fun Day, Oven Mic, dan Sharing Komik.

Kemudian melanjutkan kemampuan public speaking para komika dalam berbicara di atas panggung, berbicara adalah salah satu kemampuan khusus pada manusia. (Tarigan, 2015) adalah kemampuan mengucapkan bunyinada artikulasi atau kata-kata untuk mengekspresikan, menyatakan serta menyampaikan maksud dari pikiran, gagasan, dan perasaan. Karena stand up comedy prakteknya dilakukan didepan publik maka ada kemampuan berbicara didepan umum yang perlu komikanya perhatikan. Aspek-aspek berbicara dan kecerdasan dalam mengambil hati audiens merupakan salah satu fokus yang peneliti ingin lihat dari para komika komunitas Stand Up Indo Lampung.

Kajian penelitian ini diharapkan dapat memberikan gambaran pada peminat stand up comedy tentang pentingnya retorika dan pelatihan dalam melakukan public speaking 
Jurnal PIKMA: Publikasi Media Dan Cinema, Volume 4, No. 1, September 2021, hlm 17-24

dengan melihat dari prespektif komika komunitas

Stand Up Indo Lampung.

\section{METODOLOGI}

Penelitian ini dilakukan dengan paradigma konstruktivisme melalui pendekatan deskriptif kualitatif. (Morissan, 2013) penelitian kualitatif adalah melakukan penelitian secara mendalam, disebut sebagai in-depth method. Penelitian kualitatif berorientasi pada sejumlah kecil kasus, termasuk pada suatu studi kasus.

Paradigma Konstruktivisme sosial meneguhkan asumsi bahwa masing-masing individu selalu berupaya memahami dunia dimana mereka hidup serta bekerja. Dalam pengembangan makna-makna subjektif atas berbagai pengalaman mereka, makna-makna diarahkan kepada objekobjek atau benda-benda tertentu (Samatan, 2017).

Subjek penelitian ini adalah komika senior dan komika junior yang merupakan anggota dari komunitas Stand Up Indo Lampung, sementara objek penelitian yang berlaku dalam penelitian ini adalah segala acara dan kegiatan komunitas Stand Up Indo Lampung.

Sumber data yang akan digunakan dalam penelitian ini adalah primer dan sekunder. Data primer yang dihasilkan pada penelitian ini merupakan hasil beberapa teknik pengumpulan data yang diantaranya yaitu observasi, wawancara, dan dokumentasi yang dilakukan pada objek penelitian yaitu Komunitas Stand Up Indo Lampung. Sementara pengumpulan data sekunder akan diperoleh melalui studi kepustakaan seperti buku, jurnal, artikel, dan penelusuran secara online.

Wawancara pada penelitian dilakukan secara langsung dengan menemui 3 informan komunitas Stand Up Indo Lampung yang telah memenuhi kriteria key informan. Wawancara pertama dilakukan pada tanggal 28 April 2021 bertempat di Poco-poco Drink Sumur Batu, Bandar Lampung dan wawancara kedua dilakukan pada 4 Mei 2021 bertempat di RIDS Cafe Bandar Lampung

Dalam penelitian ini, peneliti menggunakan teknik analisis data miliki Miles and Huberman (Sugiyono, 2012) yang terdiri atas empat tahapan yaitu: pengumpulan data, reduksi data, penyajian data, dan penarikan kesimpulan terhadap seluruh rangkaian proses teknik analisis data.

\section{HASIL DAN PEMBAHASAN}

Penelitian ini membahas mengenai retorika stand up comedy, dan public speaking komunitas Stand Up Indo Lampung. Analisis data yang dilakukan didalam penelitian dilakukan dengan mengandalkan 2 teori yaitu: teori retorika Aristoteles dan teori public speaking Stephen E. Lucas.

Aristoteles (dalam West \& Turner, 2014) sangat yakin bahwa retorika dapat dimanfaatkan sebagai alat persuasi. Persuasi adalah ketika seorang komunikator dapat menarik perhatian penuh audiensnya dengan memerhatikan tiga hal tentang retoris yaitu logos (logika), pathos (emosi), dan ethos (etika/kredibilitas). 
Jurnal PIKMA: Publikasi Media Dan Cinema, Volume 4, No. 1, September 2021, hlm 17-24

Dalam retorika, penggunaan persuasi akan nampak ketika pembicara melakukan penyampaian pesan, begitu juga pada stand up comedy, kemampuan persuasi dilakukan sesuai dengan unsur pesan retorika. Terdapat 4 unsur pesan yang digunakan ketiga informan penelitian yaitu komika Mufid, komika Ghifar, dan komika Rico Pratama sebagai pedoman membuat materi stand up comedy berdasarkan ethos, pathos, logos. Menurut ketiga komika, dalam membuat pesan humor hal paling utama terdapat 4 unsur yaitu berlandaskan penjelasan yang dapat dipertanggung jawabkan dan masuk akal (Rasional). Dibuat dengan mengutamakan nilai kejujuran dan pengetahuan yang luas (Wawasan). Memanfaatkan keragaman bahasa dan budaya. Terakhir, berkomedi dengan tetap menjaga etika, nilai kesopanan, dan moral. 4 unsur pesan tersebut adalah nilai ethos, pathos, logos yang menjadi pedoman komika dalam menyusun pesan stand up comedy.

Kemudian, berdasarkan analisis yang dilakukan pada tiap-tiap informan, didapatkan bahwa 5 kanon retorika terdapat didalam kegiatan stand up comedy, karena dalam teori retorika, Aristoteles menggambarkan tentang terdapat tahapan tahapan penting dalam seseorang menyusun sebuah pidato. 5 kanon retorika Aristoteles adalah:

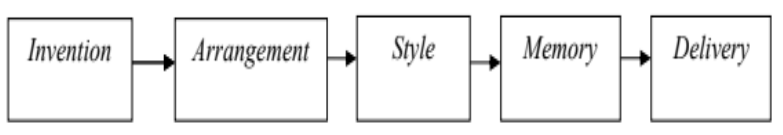

Gambar 1. 5 kanon retorika Aristoteles (dalam Littlejohn \& Foss, 2011)

Penemuan (Invention), tahap penemuan erat kaitannya dengan proses konseptualisasi seorang pembicara terhadap permasalahanpermasalahan yang akan diangkat (Littlejohn \& Foss, 2011). Ketiga komika komunitas Stand Up Indo Lampung menjelaskan bahwa tahap penemuan dalam stand up comedy dilakukan berdasarkan 2 teknik utama yaitu Observasi dan refleksi. Penemuan dalam stand up comedy biasanya adalah ide sebagai visualisasi, premis (payung pemikiran), humor, indentifikasi audiens, dan gambaran teknik penyampaian pesan.

Pengaturan (Arrangement), dalam tahap ini pembicara menyusun materi, seperti kalimat yang pantas, yang akan digunakan ketika menyampaikan materi untuk audiens (Littlejohn \& Foss, 2011). Ketiga komika komunitas Stand Up Indo Lampung menjelaskan bahwa tahap pengaturan dalam stand up comedy adalah ekplorasi-eksplorasi pada peletakan struktur beat (humor/lelucon) hingga menjadi satu kesatuan materi. Pada pengaturan para komika melakukan pemilihan gaya bahasa, dan penetapan teknik stand up comedy.

Gaya (Style), dalam tahap ini pembicara menggunakan pengunaan keragaman bahasa dan karakteristik dirinya untuk menyampaikan isi dari pidatonya (Littlejohn \& Foss, 2011). Menurut ketiga informan penelitian stand up comedy merupakan kegiatan retorika yang sangat mengutamakan gaya dalam kegiatannya, Gaya adalah tentang kejujuran menonjolkan karakter dan ciri khas dari teknik-teknik yang dikuasai dalam menyampaikan pesan. ada lebih dari 14 macam teknik-teknik stand up comedy. 
Jurnal PIKMA: Publikasi Media Dan Cinema, Volume 4, No. 1, September 2021, hlm 17-24

Memori (Memory), dalam tahap ini pembicara harus mengingat kembali tentang materi yang ditulisnya sebelum disampaikan kepada audiens (Littlejohn \& Foss, 2011). Ketiga komika komunitas Stand Up Indo Lampung menjelaskan bahwa tahap memori komika akan mengingat, melatih, dan menghafal konsep dan susunan dari kanon-kanon yang telah dilakukan sebelumnya. Ketiga informan masing-masing memiliki fokus dan metode yang berbeda dalam melakukan ingatan. Ingatan pada retorika stand up comedy didalam komunitas Stand Up Indo Lampung adalah latihan yang dilakukan secara berulang-ulang untuk mematangkan suatu materi dan humor sebelum dibawakan kepada audiens.

Penyampaian (Delivery), merupakan tahapan terakhir dalam retorika. Pembicara menyampaikan isi materinya yang telah dibuat dan di ingat. Penyampaian merupakan perwujudan simbol kedalam bentuk fisik yang mencakup berbagai pilihan mulai dari nonverbal, bicara, tulisan, hingga pesan yang diperantarai (mediated message) (Littlejohn \& Foss, 2011). Ketiga komika komunitas Stand Up Indo Lampung menjelaskan bahwa delivery adalah proses menyampaikan pesan dengan profesional dan eksekusi maksimal. Dalam melakukan delivery komika harus piawai untuk memanfaatkan keadaan audiens dan suasana panggungnya, atensi audiens diperlukan agar delivery secara sempura terjadi dan pesan humor dapat diterima dan menghibur audiens.

Kemudian peneliti berfokus mengumpulkan data kemampuan public speaking ketiga informan dan hasil yang didapat adalah Menurut data dari penjelasan ketiga informan, untuk menjadi seorang public speakers yang baik dimata audiens maka seorang pembicara harus mengutamakan kelancaran penerimaan pesan yang dilakukan audiens, dalam teknik-teknik penyampaikan pesan cara pembicara berbicara adalah dengan menampilkan karakter yang beretika, sopan dan santun sekaligus asik, jenaka, dan humoris dalam satu waktu. Ada 3 aspek penting dalam menyampaikan pidato diantaranya yaitu: metode penyampaian, suara, dan gerakan.

Methods Of Delivery (Metode Penyampaian), kategori metode penyampaian pesan dari kegiatan stand up comedy dilihat dari penjelasan ketiga informan adalah sebuah kegiatan yang berfokus pada metode speaking extemporaneously, karena stand up comedy pada prakteknya dilakukan penyusunan dan penulisan terlebih dahulu hingga materi siap untuk disampaikan kepada audiens menggunakan kefasihan teknik-teknik stand up comedy. Tetapi komika mengungkapkan bahwa pada beberapa kesempatan agar pertunjukan tidak kaku mereka juga melakukan improvisasi dengan mengandalkan kecerdasan dalam berbicara spontan.

The Speakers Voice (Suara Pembicara), kemampuan kedua adalah pengaturan suara. Menurut ketiga informan penelitian suara adalah sebuah aset emas bagi pembicara, khususnya dalam menampilkan kemampuan public speaking. Pengaturan suara yang dilakukan komika adalah ketika berkomedi komika dapat menguasai nada 
Jurnal PIKMA: Publikasi Media Dan Cinema, Volume 4, No. 1, September 2021, hlm 17-24

dan tempo yang tepat, melakukan permainan vokal dalam beberapa diksi, dan ketepatan menjeda kalimat-kalimat patahan humor.

Hal lain menurut ketiga informan pada aspek dialek yang menyertakan aksen atau logat, aksen dan logat dapat memberikan nilai lebih dan membuat audiens tertawa geli karena kekhasan dan karakteristiknya.

The Speakers Body (Gerakan Pembicara), berbicara umum dalam konteks stand up comedy, penampilan fisik di atas panggung dalam stand up comedy bukanlah aspek yang dinilai dan penting dimata audiens. Pengenaan busana terbilang bebas asalkan sopan, bersih, dan rapih. Tetapi penggunaan alas kaki tertutup diwajibkan sebagai cerminan kesopanan. Melanjuti bahasa tubuh sebagai pelengkap komunikasi non verbal, komika Komika dalam menghibur audiens perlu melakukan kontak mata sebagai penghargaan kepada audiens yang telah memberikan atensinya. Selain kontak mata, komika harus bersikap ramah dan friendly dalam menyampaikan humor, hindari kata-kata cemooh dan caci maki yang menyinggung audiens. Untuk membuat stand up comedy terasa lebih hidup komika dalam pertunjukan stand up comedy diperbolehkan mengajak audiens untuk menjadi bagian dari penampilan, gerakan menunjuk audiens, melambaikan tangan, dan mengajak berinteraksi merupakan hal lumrah untuk dilakukan.

\section{KESIMPULAN}

Berdasarkan uraian pada hasil penelitian dan pembahasan, kesimpulan yang dapat diperoleh dari penelitian ini adalah komika Komunitas Stand Up Indo Lampung mengerti penggunaan retorika pada kegiatan stand up comedy dengan baik. Pedoman pada unsur-unsur pesan retorika dilakukan agar komika dapat menghasilkan pertunjukan stand up comedy yang sempurna, dan menjadi seorang pembicara yang memiliki ethos, pathos, dan logos. Dengan tanggung jawab yang besar sebagai pembicara publik, komika menggunakan 5 kanon retorika Aristoteles dalam mempersiapkan pertunjukan stand up comedy. Lima kanon tersebut sesuai urutannya adalah penemuan, pengaturan, gaya, memori, dan penyampaian. Terakhir, ada 3 aspek paling penting menurut ketiga komika yang harus diperhatikan dalam public speaking, yaitu: metode penyampaian pesan, suara, dan gerakan.

Saran yang peneliti berikan adalah agar peminat stand up comedy terus menggali dan memperluas wawasan mengenai retorika sebagai langkah menjadi pembicara profesional dan cerdas. Kemudian, hal lain adalah agar tetap menjaga budaya-budaya yang ada didalam komunitas Stand Up Indo Lampung dan terus melakukan regerasi demi kebaikan perkembangan stand up comedy di wilayah Lampung.

\section{DAFTAR PUSTAKA}

Bakar, F.A. (2016). Implementasi Teknik Komunikasi Retorika Dalam Kegiatan Stand Up "OpenMic" Di Komunitas Stand Up Unitel. Universitas Telkom

Kurniati.I.A . (2019). Stand Up Comedy, Retorika Generasi Milenial. Ekspresi dan Persepsi, 1(2), 29-43

Littlejohn, Stephen W dan Karen A. Foss. (2011). Teori Komunikasi (Theories Of Human 
Jurnal PIKMA: Publikasi Media Dan Cinema, Volume 4, No. 1, September 2021, hlm 17-24

Communication) $9^{\text {th }}$ Edition. Jakarta: Salemba Humanika.

Lucas, Stephen E. (2012). The Art Of Public Speaking $11^{\text {th }}$ Edition. New York: McGraw-Hill.

Morissan. (2013). Teori Komunikasi: Individu Hingga Massa. Jakarta: Kencana.

Mulyana, Deddy. (2014). Ilmu Komunikasi: Suatu Pengantar. Bandung: PT Remaja Rosdakarya.

Muhammad, O. (2017). Gaya Komunikasi Comic Komunitas Stand Up Indo PKU Pekanbaru. JOM Fisip, 4(1), 1-15

Novita, I. (2019). Analisis Sarana Retorika Dalam Stand Up Comedy Raditya Dika. Bahastra, 3(2), 126-132

Nugroho, P. 2012. Potret Stand Up Comedy: Strategi Menjadi Comedian Handal. Yogyakarta: Pustaka Baru Press.

Samatan, N. (2017). Riset Komunikasi II. Jakarta: Penerbit Gunadarma.

Sugiyono. (2012). Metode Kualitatif, dan $R \& D$. Bandung: Alfabeta.

Tarigan, H.G. (2015). Berbicara Sebagai Suatu Keterampilan Berbahasa. Bandung: Angkasa.

West, Richard. (2014). Pengantar Teori Komunikasi: Analisis dan Aplikasi $3^{\text {rd }}$ Edition. Jakarta: Salemba Humanika. 